\title{
Loud Music Listening
}

\author{
Nicolae Petrescu*
}

\begin{abstract}
Over the past four decades, there has been increasing interest in the effects of music listening on hearing. The purpose of this paper is to review published studies that detail the noise levels, the potential effects (e.g. noise-induced hearing loss), and the perceptions of those affected by music exposure in occupational and non-occupational settings. The review employed Medline, PubMed, PsychINFO, and the World Wide Web to find relevant studies in the scientific literature. Considered in this review are 43 studies concerning the currently most significant occupational sources of highintensity music: rock and pop music playing and employment at music venues, as well as the most significant sources of non-occupational high-intensity music: concerts, dicotheques (clubs), and personal music players. Although all of the activities listed above have the potential for hearing damage, the most serious threat to hearing comes from prolonged exposures to amplified live music (concerts). The review concludes that more research is needed to clarify the hearing loss risks of music exposure from personal music players and that current scientific literature clearly recognizes an unmet hearing health need for more education regarding the risks of loud music exposure and the benefits of wearing hearing protection, for more hearing protection use by those at risk, and for more regulations limiting music intensity levels at music entertainment venues.
\end{abstract}

Keywords: noise-induced hearing loss, music, occupational noise, health knowledge, health attitudes, ear protective devices

\section{INTRODUCTION}

Noise-induced hearing loss (NIHL) refers to a gradual, cumulative and preventable decline in auditory function that follows repeated exposure to loud noise. It is the leading cause of preventable hearing loss $(1,2)$. It is also estimated that $10 \%$ (30 million) of Americans are encountering hazardous levels of noise, that $25 \%$ of those working in the construction, mining, agriculture, manufacturing, transportation, and military industries routinely encounter noise leves above $90 \mathrm{~dB}$ (A), and that such noise exposure has already generated a sizeable population of workers who meet the Occupational Safety and Health Administration's (OSHA) definition for "material impairment of

*To whom correspondence should be addressed:

Nicolae Petrescu

33 Wood Street, apartment 2909

Toronto, ON, Canada

M4Y 2P8

Telephone: $647-838-3372$

Email: nicolae.petrescu@utoronto.ca hearing" (over $25 \mathrm{~dB}$ threshold at 1000, 2000, and 3000 $\mathrm{Hz}$ ). Since workers experiencing such losses can have significant effects on their employment, social interactions, and family interactions, protecting hearing health in the workplace has become an important undertaking. Occupational exposure to noise programs and regulations (for e.g. maximum allowed daily noise doses) have been designed $(3,4)$, but no standards have been set for recreational noise, an emerging contributor to noise-induced hearing loss (5). There are numerous sources of non-occupational noise exposure. Clark and Bohne (6) have compiled a partial list of significant sources of leisure noise, and music figures prominently in their construct. Music, in addition, transcends the recreational setting to pose an occupational risk of NIHL for groups such as music venue workers and music performers $(7,8)$.

Three decades ago, experts in the field suggested that damage risk criteria be set for music using temporary threshold shift measurements (9). Temporary threshold shift (TTS) refers to the temporary hearing impairment 
that usually occurs after exposure to

intense noise, the threshold being the quietest sound distinguished by the subject. TTS is known to increase in constant noise in direct proportion to the logarithm of exposure time and to decay in inverse proportion to the logarithm of recovery time(9). It is now widely accepted that repeated TTSs can lead to accumulated cellular damage which can cause permanent threshold shifts (PTS) (2). The precise relationship between temporary and permanent threshold shifts has not yet been elucidated, and TTS cannot be used to predict the magnitude of PTS(2), but according to an animal study, TTS is considered to be a good predictor of early development of PTS(10). For more details on the manifestation of TTS and PTS phenomena at the cellular level readers are directed to articles by May (1) and Clark et a.(42).

The purpose of this review is to summarize the scientific literature concerning exposure to music as a risk of NIHL, an important health concern. An exhaustive review of all the relevant literature is beyond the scope of this paper; for an extensive review of this topic, the reader is referred to Davis et al(11). The present review is limited to what could be considered the major sources of occupational and non-occupational music exposures. For each type of exposure, the review summarizes data on noise emissions, information on the knowledge, attitudes, behaviors, and effects on those at risk, and, where possible, an assessment of hearing damage risks. Wherever sources were found to be contradictory, attempts were made to examine the quality of the studies and draw the most reasonable conclusions.

\section{METHODS}

A literature search was performed using Medline (1950 to May 2007), Pubmed, PsychINFO, and the World Wide Web. Only English language articles were reviewed. The search was performed with both subject headings and free text words to increase the sensitivity of the search. Searches were performed using a number of key words and phrases, used alone or in combination: music, noise, occupational, noise-induced hearing loss, recreational noise exposure, rock music, discotheque, personal listening devices, attitudes, prevention, hearing protector, ear plugs, and hearing protecting device. The references listed by the identified relevant studies were also scrutinized for additional useful citations. No specialists in the field or authors were contacted for unpublished data. The collected published studies were read in their entirety, and the information most pertinent to the present study was included in the review. The author used a simple method, abbreviated as ODDCHAIR, to review each article and to determine the quality of the particular study. The objectives, design, definitions of the study as well as the data collection, handling, analysis, interpretation, and reporting (ODDCHAIR) were clearly identified for each study before inclusion in the review.

\section{LITERATURE FINDINGS}

\section{Music Exposure: Occupational Setting}

\section{Musicians}

Rock musicians have been found to be at a significant risk of music-based NIHL. A publication which reviewed seven publications concerning the hearing of rock musicians found that an average of $20 \%$ of rock musicians suffer from permanent hearing loss, the prevalence ranging from 5 to $41 \%(7)$. This review also found that hearing disturbances like tinnitus and hyperacusis (a collapsed tolerance to normal environmental sounds) appear significantly more often in rock musicians than in non-musicians(7). A study that examined a group of 139 rock and jazz musicians found that $74 \%$ suffered from one or a combination of multiple hearing disorders: hearing loss, tinnitus, hyperacusis (sounds of low intensity are uncomfortably loud), distortion, and/or diplacusis (hearing the same tone at two different pitches), with the first three being the most commonly reported disorders(12). The study also found that tinnitus and hyperacusis were found in musicians significantly more frequently than in reference populations(12). In addition, two studies that investigated pop/rock musicians found interesting results. One found that after five years of playing music, a group of pop/rock Swiss musicians that never wore hearing protection experienced permanent moderated hearing loss ( $6 \mathrm{~dB}$ of threshold enhancement compared to the control group), hyperacusis (26\%), and tinnitus (17\%), while a group that regularly wore hearing protection showed minimal average hearing threshold increase $(0.9 \mathrm{~dB})(7)$. On the other hand, a study covering 53 Swedish and British pop and rock musicians found that after sixteen years of music playing, only $15 \%$ of them experienced any hearing loss on objective audiometric measurements(14). This was surprising since sound levels at rock concerts routinely reach sound levels above $100 \mathrm{~dB}(5,15,16)$ which are considered unsafe for any unprotected exposures exceeding fifteen minutes $(3,4)$.

Symphony orchestra musicians may also be at risk of occupational music-induced NIHL(17). Jansson and Karlsson attempted to map the sound levels in a symphony orchestra and found that 'heavy' symphonic music, such as that experienced by musicians immediately in front of trumpets, exceeds the permitted dose for industrial noise equivalent after only ten hours 
of weekly playing(18). A study undertaken in England also showed the potential for hearing loss in classical orchestral musicians, as trumpet and piccolo players receive noise doses $160 \%$ and $124 \%$ respectively of the then (1992) national occupational standard (namely 90 $\mathrm{dB}$ for 8 hours)(19). Royster et al (20) found that during practices and concerts, the average industrial noise equivalent exposure of classical musicians is like that of a standard working day ( 8 hours) at $85.5 \mathrm{~dB}$, only slightly above the recommended safe threshold of 85 $\mathrm{dB}$ in industrial occupational settings $(3,4)$. However, they also observed notched audiograms consistent with noise-induced hearing damage in $52.5 \%$ of individual musicians, noting that violinists and violists showed poorer thresholds (in the 3-6 kHz range) in the left ear when compared to the right, consistent with the left ear's greater exposure through proximity to the sound source(20). Notched audiograms and poorer left-ear thresholds were also detected by Ostri et al.(21) who studied 95 musicians of the Royal Danish Theater. They found hearing deficits (qualified as $20 \mathrm{~dB}$ or more over normal hearing thresholds in frequencies between 3 and $6 \mathrm{~Hz}$ ) in $58 \%$ of the participants (21).

Not all studies showed hearing deficiencies in orchestra musicians, however. In a 16-year follow-up study, Kahari et al (22) found that 56 classical musicians experienced no extended negative progress in their pure-tone hearing threshold values. A larger study, working with a population of 417 musicians, showed that when compared to reference values, classical musicians' measured tone thresholds did not differ significantly from those of normal controls (nonmusicians and no significan noise exposure population from Spoor \& Passchier-Vermeer (53)), although the measured sound exposure in some situations exceeded the recommended sound level exposures to industrial noise (23). Of note, the authors also reported on a $10 \mathrm{~dB}$ threshold enhancement over the high frequencies $(6000$ $\mathrm{Hz}$ and beyond) in flute players as well as a $30 \mathrm{~dB}$ left ear threshold increase for double bass players, in the 4000-8000 frequency range. At least 123 of the assessed professional musicians had been playing music for over 6 years at the time of the study(23).

One study showed that disc jockeys (DJs) are at substantial risk for developing noise-induced hearing loss, as average sound levels reached $96 \mathrm{~dB}$ during observed performances(24). Seventy per cent of the 23 DJs taking part in the study reported TTSs after playing sessions, and $74 \%$ reported post-exposure tinnitus(24).

\section{Employees of music venues}

According to a study that investigated eight livemusic clubs in the United States, employees of establishments hosting regular live music performances were found to be exposed to sound levels ranging from 94.9 to $106.7 \mathrm{Db}(25)$. The study also found that symptoms of sound exposure (tinnitus) and subjective threshold shifts correlated with the sound intensity and that only $16 \%$ of the employees reported regularly using hearing protection(25). University students working part-time jobs in a campus music entertainment venue were found to be regularly exposed to sound intensities averaging $90 \mathrm{~dB}$; the same study found moderate postexposure temporary threshold shifts (TTSs) that correlated well with personal exposure doses and permanent hearing loss of more than $30 \mathrm{~dB}$ at various frequencies in the 250 to $6000 \mathrm{~Hz}$ range in $29 \%$ of the subjects (26).

\section{Music Exposure: Recreational Setting}

Two significant studies revealed the frequency and habitual exposure to music in the recreational setting. Mercier and Hohmann(27) surveyed a group of 700 Swiss young men and women, aged 16 to 25 , and found that, overall, $79 \%$ of the subjects regularly attend discotheques ( $76 \%$ once or less per week, $19.6 \%$ twice per week, $4.8 \%$ thrice per week, and $1.3 \%$ at least thrice per week), $52 \%$ pop and rock concerts, and 35\% techno parties (e.g. raves) (pop, rock, techno combined: $68.2 \%$ once or less per week, $13.3 \%$ twice per week, $4.9 \%$ thrice per week, and $13.6 \%$ more than thrice per week). In all cases, nearly $75 \%$ of the population had been upholding their particular habits for at least one year. Furthermore, $71 \%$ of those surveyed had suffered tinnitus following attendance at a music event and $11 \%$ had audiometry-confirmed hearing damage (27). Eggemann et al(28). reporting only on exposures in youngsters aged 14 to 20 , found their populationexposed to an average of 3 hours of music listening daily, via concerts, discotheques, and headphones. Among others, they found that $85 \%$ of those surveyed attend clubs and concert venues where music sound intensity ranged from 89 to $110 \mathrm{~dB}$ (A), while $10 \%$ of those who regularly listened to music through headphones ( $80 \%$ of all surveyed) were found to be exposed to average sound intensities of $100 \mathrm{~dB}$ (A).

\section{Concerts}

Concerts attendees have been repeatedly found to suffer hearing damages from exceedingly high music sound intensities, rock concerts being the settings of highest risk. On average, rock concert sound levels exceed $100 \mathrm{~dB}(\mathrm{~A})(5,15,16)$ unsafe for any exposure lasting longer than 15 minutes $(3,4)$. Classical music concerts are not considered to pose any risk of NIHL because attendance habits do not exceed twenty hours per week and average exposures are less than $90 \mathrm{~dB}$ 


\section{(A) $(29,30)$}

A number of the earliest studies on the effects of rock music concerts on attendants' hearing found TTSs of up to $30 \mathrm{~dB}$ at the $4 \mathrm{kHz}$ frequency mark of the hearing spectrum $(5,31,32,33)$. More recent studies support these findings $(15,16,34)$. A Canadian study found that $81 \%$ of 22 rock concert attending volunteers showed a TTS of $10 \mathrm{~dB}$ or more 5 to 25 minutes after a concert, while 50 minutes after the concert, $76 \%$ showed continued TTS(15). A prospective, randomized study in which 29 volunteers attended non-consecutive rock and pop concerts found that $64 \%$ of those not wearing ear plugs experienced significant threshold shifts compared to the $27 \%$ incidence of TTS in those who used ear plugs(16). Another study that investigated the risk of hearing loss from short-term exposures to high sound levels found that a group of 24 patients requiring rheologic therapy for acoustic trauma reported impairment symptoms after exposures to rock or pop concerts $(67 \%)$; discothques $(17 \%)$, parties $(12 \%)$, and cassette players $(4 \%)(34)$. The maximum threshold changes, reaching $40-60 \mathrm{~dB}$, were in the $3-4 \mathrm{kHz}$ range, and all patients suffered from tinnitus. Interestingly, only $33 \%$ of these patients experienced an improvement in tinnitus following hearing rehabilitation, while all patients benefited froman improvement in hearing loss through therapeutic intervention (34). Tinnitus was also found to be a very common ( $84.7 \%$ ) form of hearing disturbance in a group of rock concert attendees surveyed by Bogoch et al.(35) and in 61\% of those participating in an MTV web survey completed by 9693 subjects (36).

In terms of long-term hearing deficits, a significant increase in average hearing thresholds in the 0.5 to 8 $\mathrm{kHz}$ range compared to matched controls (age and sex matched subjects who rarely attend rock and variety concerts) was found in 87 individuals aged 12 to 40 who attend concerts (measured sound intensity of 100 to 115 $\mathrm{dB}(\mathrm{A})$ ) at least twice per month(37). Another study that focused on the long-term effects of listening to amplified music found that a group of 505 university students with a high self-reported rate (at least one event per month) of pop music event attendance (concerts and discos) exhibited statistically significant hearing losses compared to a control group (attended less than four events per year) (38). With regards to perceptions regarding loud music, Bogoch et al.(38) found that $75 \%$ of the surveyed rock concert attendees thought it was at least somewhat likely that sound levels at music concerts can damage hearing, $11.4 \%$ did not think that to be the case, and $14.4 \%$ did not know what effects concert sound levels can have. Concerning a wide variety of publicly played music, a European study looking at the perceptions of 700 participants found that
$35 \%$ of those surveyed thought pop and rock concerts are too loud, $39 \%$ held a similar view of techno parties, and $42 \%$ considered discotheque music to be too $\operatorname{loud}(27)$.

\section{Discotheques}

Discotheque sound levels are similarly hazardous to hearing as they can cause significant tinnitus and significant temporary hearing loss in the $3-4 \mathrm{kHz}$ range(34). Lending support to these findings, a webbased survey reported that $43 \%$ of those participating experience tinnitus after attending clubs(36). Such findings are less surprising in light of reports on music sound levels in discotheques routinely exceeding $90 \mathrm{~dB}$ (A) (26) and occasionally $100 \mathrm{~dB}$ (A)(28). A number of studies on attitudes and behaviours regarding discotheque music levels have been undertaken by an Austrian group, Weichbold and Zorowka. They examined whether adolescents (ages 14-19) exhibit preventive behavior when attending discotheques if informed on the risks of hearing-damage from loud music; surprisingly although $85 \%$ of 253 were informed of the risks, awareness improved the appraisal of music loudness yet had no effect on disco attendance frequency or use of ear plugs(39). Next, the same investigators analyzed the effect of a hearing education campaign on hearing-protective behavior and revealed a moderate change in hearing-protective behavior: frequenting discos at a rate of ten times in six months decreased from $34 \%$ to $24 \%$, and the use of earplugs increased from $0 \%$ to $3.7 \%$ post-campaign(40). In a following study, Weichbold and Zorowka investigated the efficacy of hearing impairment preventive measures if such measures were to become the responsibility of the music venue; they surveyed over one thousand high school students to find the effects of lowering disco music levels on student behaviour. The study found that $43.8 \%$ of those surveyed wanted a decrease in music volume, while only $2.5 \%$ would like an increase $(41)$. In the case of a moderate decrease in music volume, $5 \%$ of those surveyed would decrease disco attendance, 10\% would increase their attendance, and the rest would not change attendance habits(41).

\section{Personal music players}

The role of personal music players (PMPs) (walkman, diskman, mp3 players, etc.) in music induced hearing loss is not clear, although ownership of such devices has been quoted as high in the past(5), is believed to be increasing(42), and several studies have reported risky exposures $(43,44)$. One study found that 16 volunteers who regularly used their PMPs averaged three hours of music listening per day at an average of $92 \mathrm{~dB}$ (A),(43) while a more recent investigation, Hellstrom et al.(44) 
reported listening habit findings of daily hour-long listening at intensities in the range of 91-97 dB (A). In the latter study, subjects were advised to listen for one hour to "loud but still comfortable music level" aiming to investigate discomfort perceptions as well as changes in hearing post-exposure. Both studies reported positive TTSs for all of their subjects 60 minutes postexposure $(43,44)$. Other investigators show reason for no concern regarding the risks of PMP use to hearing health $(45,46)$. Upon not finding, respectively, no convincing evidence of permanent hearing damage(45) and only mild post-use TTS in one population(46), Mostafapour et al. (45) and Turunen-Rise et al.(46), concluded that the risk of acquiring permanent NIHL from use of PMPs is very small. Lastly, several studies form the middle ground of the dispute. In one instance, hearing damage from PMPs has been documented as increased hearing thresholds in 54 subjects using their devices for longer than 7 hours per week, compared to nearly normal thresholds in 195 subjects using PMPs only 2-7 hours per week(37). In a survey of 52,000 young male subjects, Buffe et al.(47) concluded that only listeners who habitually exceed 7 hours of moderate (average intensities between 70 and $80 \mathrm{~dB}$ (A)) music intensity listening per week are at risk of developing permanent music-induced hearing loss.

\section{DISCUSSION}

The reviewed literature shows the significant risks of noise-induced hearing loss (NIHL) from music playing in rock musicians $(7,12,13)$. Only one study on the topic found no significant hearing damage in rock and pop musicians after twenty-six years of professional playing(14). The authors were surprised by the findings and proposed that "there might be a protective effect by the generally positive attitude from the musicians toward their performance and audience;"(14) notably, they neglected to make mention of the fact that the study did not inquire into the use of hearing protection nor did they consider significant that only 53 out of the 83 initially participating musicians (26 years prior) participated in the followup threshold measurement study. Most significantly, however, the difference in findings can be explained by the authors' high threshold for reporting hearing impairment; while Axelsson et al.(14) consider pure tone audiogram threshold under 20 $\mathrm{dB}$ and very limited $(>25 \mathrm{~dB})$ high frequency loss as well preserved hearing, other rock musician study authors report notable hearing impairments in musicians averaging $10-15 \mathrm{~dB}$ threshold enhancement. In light of this and the heterogeneity of rock music performing environments, which is difficult to control for, it is unreasonable to consider the discrepancy between these study findings as significant.
Since rock music-induced hearing loss risks have been clearly established, Hearing Education and Awareness for Rockers (H.E.A.R.), an organization created by veteran musicians, among them Pete Townsend of The Who, has taken a strong initiative in educating the public on the dangers of excessive music sound exposure as well as in providing free hearing protecting ear plugs at various concerts and venues in the San Francisco Bay area(48). Since their inauguration in 1990, H.E.A.R. has been creating public service announcements, enlisting the help of famous musicians such as Mick Fleetwood of Fleetwood Mac and Lars Ulrich of Metallica, and has strongly encouraged hearing protection use during concert attendance for both music fans and musicians(48). The protective effect of ear plugs in music professionals has been mentioned and encouraged for both rock musicians(13) and orchestra musicians(17) in studies included in this review. Since musicians represent a group especially dependent on optimally functional hearing, other proposed strategies to improve musician hearing health, such as regular evaluations for types of loud-music induced hearing problems other than hearing loss (tinnitus, hyperacusis, and diplacusis) and continued education about the risks to hearing and the benefits of ear protection(13) should be taken seriously.

Furthermore, similar strategies should be used for symphony orchestra musicians, although the risk of music-induced hearing loss is not as clearly defined for the whole of this population $(22,23)$.

Both studies regarding employees of music venues agree on the reality of a substantial risk of developing NIHL from occupational exposure to loud music $(25,26)$. Their prevention strategies differ, however, since Gunderson et al.(25) suggest that hearing conservation programs should be developed for this occupational subgroup, while Sadhra et al.(26) suggest that the next appropriate steps should be to better educate employees about the risks and to improve noise exposure assessments in entertainment venues. Although different in their implication of hearing safety responsibility and readiness to enact change, both approaches are important to improve hearing health in this population.

In the non-occupational setting, high-intensity music listening has been clearly linked to temporary hearing impairment and disturbances in the setting of pop and rock music concerts $(15,16,34,35,36)$. Meanwhile, data on discotheque attendees although sparse, shows considerable rates of post-exposure tinnitus in those attending $(34,36)$; temporary threshold shifts have so far not been documented(37). Nevertheless, measured sound intensities alone are enough to suggest the possibility of hearing damage risks for discotheque 
attendants(28).

An interesting conclusion can be drawn from the three studies undertaken by Weichbold and Zorowka: in the high-school age population under study, information on hearing risks alone leads to significantly limited hearing protection behaviour. Although this finding may yet be key in planning future prevention programs, such a conclusion undermines the value of risk education and must not be accepted without caution, for the information and educational campaigns mentioned and undertaken in these studies can reasonably be assumed to have a variety of impacts on their target population. These impacts may, for example, not be noticed because the post-educational assessment happens a year after the educational program. It is commendable that the course (PROjectEAR) consists of four 45-minute sessions, spread over three days, and uses not only a variety of didactic approaches (multimedia, demonstrations, roleplay, and creative group work) but also interactions with patients that are hearing impaired and suffering from tinnitus. It may, however, be too short-lived to create an impact on healthy music listening behaviour. Alternatively, as also noted by Folmer et al.(54), educational sessions may have a positive impacts on knowledge and on attitudes, but may not be sufficient for behaviour change; this conclusion implies the need for further awareness and attitudes studies on this population and directs future prevention efforts towards introducing new interventions aimed at improving the chances of desirable impacts on adolescent hearing health behaviour.

Education about the hearing risks of loud music exposure can still play an important role in hearing health protection, as Chung et al.(36) showed that although only $14 \%$ of over nine thousand young adult responders to a web based survey reported using hearing protection, $66 \%$ could be motivated to try ear protection if they were aware of the potential for permanent hearing loss.

The dangers of listening to personal music players have been difficult to define because of the lack of consensus in the literature. While concluding that more studies should be undertaken to clarify risks, it could also be useful to agree to a temporary consensus guided by findings suggesting that using PMPs for less than seven hours per week at moderate volumes is not likely to cause NIHL, while listening in excess increases the risk of music-induced $\operatorname{NIHL}(47,48)$. Increasing the knowledge of the risks to hearing from listening to PMPs is certainly advisable in light of the accepted and increasing popularity of such devices(42).

Besides awareness of the risks of music-induced hearing loss, attitudes are also important in protecting the hearing of those at risk. Interestingly, the Chung et al(36). study found that only $8 \%$ of those participating in the web-based survey thought hearing loss "a very big problem." On the other hand, investigating the willingness to wear hearing protection found promising results; as mentioned previously, $66 \%$ could be motivated to try hearing protection if they were aware of the risks of permanent hearing loss.

Furthermore, despite very low current usage of hearing protection among young music lovers $(35,36)$, $85 \%$ of those surveyed by Crandell et al.(49) and $42.1 \%$ of those surveyed by Bogoch et al.(35) said they would wear hearing protection at concerts if it were freely provided. The same two studies reported a significantly common self-reported reason for not wearing ear plugs: "it would not look good." $(35,49)$ With an outlook to a remedy, Bogoch et al.(35) suggest that if more concert attendees wore hearing protection and if hearing protection became normal attire at concerts, such negative perceptions of self-image would fade.

The studies presented in this review are those most recently part of the literature. If no clear answer has been provided here regarding certain aspects of the risks of loud music exposures, it is due to the lack of consensus on the topic in the literature. Of the weaknesses of this review, two are very important. The review only included articles published in English, while a number of the articles found initially were published in other languages. Time and resource restraints did not permit translating and using these resources. Secondly, this study attempts to elaborate on the sources of music-induced hearing loss that the author has found most important, and it has consciously restricted the review to those only, choosing to not address several other occupational and nonoccupational sources of potentially dangerous loud music exposures. In partial reparation for such omissions, the author suggests the reviews by Clark (5) and Davis et al.(11).

There have been proposed explanations, albeit not formally investigated, for why, despite knowledge of the risks, loud music exposure continues. Conservative sources have suggested that since sounds are not clearly offensive to the ear until they reach 120 $\mathrm{dB}$ (A) (28), and since TTS is often insidious(15), the exposure of those not yet affected by NIHL continues unabated. A bolder study mentions the unique response in listeners to the sound of music: unlike other sounds (airplanes, lawn mowers, etc.), music can be played quite loudly without becoming annoying, especially if the music is well liked(50). Calvert and Clark have coined the term "social noise phenomenon" to describe the tendency of youths and young adults to frequent discotheques, hypothesizing that high levels of noise prevent communication at distances greater than a few 
feet, thus encouraging and allowing those who seek members of the opposite sex to move inside "personal space" in order to communicate(51). Finally, a study conducted by Florentine et al.(52) found that 8 out of 90 surveyed music listeners showed a pattern of maladaptive loud-music listening behaviour similar to that exhibited by the drinking behaviours of alcohol addicts. The group found that, according to the clinical conceptualization of an addictive syndrome, the 8 subjects scored above diagnostic threshold criteria on the NEMLS (Northeastern Excessive Music Listening Survey), a questionnaire based on the MAST (Michigan Alcoholism Screening Test) and on criteria used in the formal assessment and treatment of people with addictions. These individuals were found to be similar to addicts via their self-reported maladaptive musiclistening behaviour based on criteria such as continued listening despite negative consequences (e.g. tinnitus) and tolerance for loud music.

These hypotheses indicate that there is still much to investigate and uncover regarding music exposure as a risk for noise-induced hearing loss. While questions about exposures, effects, attitudes, and behaviours in the music-listening settings of work, leisure, and changing technologies await answers, there is currently ample evidence to strongly support establishing and ongoing efforts to educate and protect the public, music professionals, and music venue employees from the hazards of high intensity music exposure.

\section{ACKNOWLEDGMENTS}

The author would like to thank Dr. Ron House for his crucial support throughout the project's duration, Dr. Isaac Bogoch for the impetus he provided to the project idea, and Dr. Rob Sargeant whose expertise and guidance has been very helpful.

\section{REFERENCES}

1. May JJ. Occupational hearing loss. Am J Indust Med 2000; 37:112-20.

2. Consensus National Conference. Noise and hearing loss. JAMA 1990; 263:3185-90.

3. Canadian Centre for Occupational Health and Safety [homepage on the Internet]. Hamilton: The Centre; c2007. [updated 2007 Mar 19; cited 2007 May 20]. Available from: http://www.ccohs.ca/oshanswers/phys_agents/exposure_can.ht $\mathrm{ml}$

4. American Academy of Audiology [homepage on the Internet]. Reston: The Academy; c2007 [updated 2003; cited 2007 May 20]. Available from: www.audiology.org/publications/ documents/positions/Hearingconservation/

5. Clark WW. Noise exposure from leisure activities: A review. J Acoust Soc Am 1991;90(1):175-81.

6. Clark WW, Bohne BA. The effects of noise on hearing and the ear. Med Times. 1984 122, 17-22.

7. Stormer CC, Stenklev NC. Rock music and Hearing Disorders. Tidsskr Nor Laegeforen. 2007 Mar 29; 127(7):874-7.

8. www.hearnet.com [homepage on the Internet]. San Francisco:
Hearing Education and Awareness Rockers, Inc.; c1991-2006 [cited 2007 May 20]. Available from: http://www.hearnet.com/ index.shtml

9. Dey F. Auditory fatigue and predicted permanent hearing defects from rock and roll music. $\mathrm{N}$ Eng $\mathrm{J}$ Med 1970;282(9):467-70.

10. Luz GA, Fletcher JL, Fravel WJ, Mosko JD. The relation between TTS and PTS in rhesus monkeys exposed to impulse noise. Acta Otolaryngol Suppl (Stockh) 1973;Suppl 312:5-15.

11. Davis AC, Fortnum HM, Coles RRA, Haggard MP, Lutman ME. Damage to hearing from leisure noise: A review of the literature. MRC Institute of Research. Nottingham, 1985.

12. Kahari K, Zachau G, Eklof M, Sandsjo L, Moller C. Assessment of hearing and hearing disorders in rock/jazz musicians. Int $\mathrm{J}$ Audiol 2003;42:279-288.

13. Schmuziger N, Patscheke J, Probst R. Hearing in nonprofessional pop/rock musicians. Ear Hear. 2006 Aug;27(4):321-30.

14. Axelsson A, Eliasson A, Israelsson B. Hearing in pop/rock musicians: a follow-up study. Ear Hear. 1995 Jun;16(3):245-53.

15. Yassi A, Pollock N, Tran N, Cheang M. Risks to hearing from a rock concert. Can Fam Physician. 1993 May;39;1045-50.

16. Opperman DA. Reifman W. Schlauch R. Levine S. Incidence of spontaneous hearing threshold shifts during modern concert performances. Otolaryngol Head Neck Surg. 2006 Apr 134(4):667-73.

17. Teie PU. Noise-induced hearing loss and symphony orchestra musicians: risk factors, effects, and management. Md Med J. 1998 Jan;47(1):13-8.

18. Jansson E, Karlsson K. Sound levels recorded within the symphony orchestra and risk criteria for hearing loss. Scand Audiol 1983;12(3):215-21.

19. McBride D, Gill F, Proops D, Harrington M, Gardiner K, Attwell C. Noise and the classical musician. BMJ. 1992 Dec 1926;305(6868):1561-3.

20. Royster JD, Royster LH, Killion MC. Sound exposures and hearing thresholds in symphony orchestra musicians. J Acoust Soc Am. 1991 Jun;89(6):2793-803.

21. Ostri B. Eller N. Dahlin E. Skylv G. Hearing impairment in orchestral musicians. Scand Audiol. 1989;18(4):243-9.

22. Kahrari KR, Axelsson A, Hellstrom PA, Zachau G. Hearing development in classical orchestral musicians. A follow-up study. Scand Audiol. 2001;30(3):141-9.

23. Karlsson K, Lindquist PG, Olaussen T. The hearing of symphony orchestra musicians. Scand Audiol. 1983;12(4);25764.

24. Bray A, Szymanski M, Mills R. Noise induced hearing loss in dance music disc jockeys and an examination of sound levels in nightclubs. J Otolaryngol Otol. 2004 Feb; 118(2):124-8.

25. Gunderson E, Moline J, Catalano P. Risks of developing noiseinduced hearing loss in employees of urban music clubs. Am J Ind Med. 1997 Jan; 31(1):75-9.

26. Sadhra S, Jackson CA, Ryder T, Brown MJ. Noise exposure and hearing loss among student employees working in university entertainment venues. Ann Occup Hyg. 2002 Jul; 46(5):455-63.

27. Mercier V, Hohmann BW. Is Electronically Amplified Music too Loud? What do Young People Think? Noise Health. 2002;4(16):47-55.

28. Eggemann C, Koester M, Zorowka P. [Hearing loss due to leisure time noise is on the rise. The ear also needs a rest period] MMW Fortschr Med. 2002 Dec 5;144(49):30-3.

27. Barry JP, Thomas IB. A clinical study to evaluate rock music, symphonic music and noise as sources of acoustic trauma. J Aud Eng Soc 1972;20:271-4.

29. Fearn RW. Level limits of music. J Sound Vib 1975;43:588-91.

30. Ulrich RF, Pinheiro ML. Temporary hearing losses in teenagers 
attending repeated rock-and-roll sessions. Acta Otolaryngol 1974;77:51-55.

31. Clark WW, Bohne BA. Temporary hearing losses following attendance at a rock concert. J Acoust Soc Am Suppl 1.1986;79:S48.

33. Danenberg MA, Loos-Cosgrove M, and LoVerde M. Temporary hearing loss and rock music. Lang Speech Hear Serv Schools 1987;18:267-74.

34. Metternich FU, Brusis T. [Acute hearing loss and tinnitus caused by amplified recreational music] Larnygorhinootologie 1999 Nov;78(11):614-9.

35. Bogoch I, House RA, Kudla I. Perceptions about hearing protection and noise-induced hearing loss of attendees of rock concerts. Can J Public Health. 2005 Jan-Feb;96(1):69-72.

36. Chung JH, Des Roches DM, Meunier J, Eavey RD. Evaluation of noise-induced hearing loss in young people using a webbased survey technique. Pediatrics. 2005 Apr;115(4):861-7.

37. Meyer-Bisch C. Epidemiological evaluation of hearing damage related to strongly amplified music (personal cassette players, dicotheques, rock concerts)-high definition audiometric survey on 1364 subjects. Audiology. 1996 May-Jun;35(3):12142.

38. Hanson DR, Fearn RW. Hearing acuity in young people exposed to pop music and other noise. Lancet. 1975 Aug 2;2(7927):2035 .

39. Weichbold V, Zorowka P. [Effect of information about hearing damage caused by loud music. For adolescents the music in discoteques is too loud despite loudness limits]. HNO. 2002 Jun;50(6):560-4. German.

40. Weichbold V, Zorowka P. Effects of a hearing protection campaign on the discotheque attendance habits of high-school students. Int J Audiol. 2003 Dec;42(8):489-93.

41. Weichbold V, Zorowka P. [Will adolescents visit discotheque less often if sound levels of music are decreased?]. HNO. 2005 Oct;53(10):845-8, 850-1. German.

42. Clark WW, Bohne BA. Effects of noise on hearing. JAMA. 1999 May 5;281(17):1658-9.

43. Lee PC, Senders CW, Gantz BJ, Otto SR. Transient sensorineural hearing loss after overuse of portable headphone cassette radios. Otolaryng Head Neck Surg. 1985;93:625-33.

44. Hellstrom PA, Axelsson A, Costa O. Temporary threshold shift induced by music. Scandinavian Audiology. 1998;48:87-94.

45. Mostafapour SP, Lahargoue K, Gates GA. Noise-induced hearing loss in young adults: the role of personal listening devices and other sources of leisure noise. Laryngoscope 1998 Dec;108(12):1832-9.

46. Turunen-Rise I, Flottop G, Tvete O. Personal cassette players ('Walkman'). Do they cause noise-induced hearing loss? Scand Audiol 1991;20:239-44.

47. Buffe P, Cudennec YF, Ben Azzouz M, Bassoumi T, Ferron JJ. Survey on the harmfulness of listening to music with headphones. Ann Otolaryngol Chir Cervicofac. 1986;103(5):351-5.

48. www.hearnet.com [homepage on the Internet]. San Francisco: Hearing Education and Awareness Rockers, Inc.; c1991-2007 [cited 2007 May 19]. Available from: http://www.hearnet.com/index.shtml

49. Crandell C, Mills TL, Gauthier R. Knowledge, behaviours, and attitudes about hearing loss and hearing protection among racial/ethnically diverse young adults. Journal of The National Medical Association. 2004:96(2):176-86.

50. Kuwano S, Namba S, Florentine M, Zheng D, Hashimoto T. Factor analysis of the timber of noise-comparison of the data obtained in three different laboratories. Proc Acoust Soc Japan. 1992 N92-4-3, 559-60.

51. Calvert DR, Clark WW. The Social Noise Phenomenon: Newsnotes. Central Institute for the Deaf. St. Louis, 1983.

52. Florentine M, Hunter W, Robinson M, Ballou M, Buus S. On the behavoiural characteristics of loud-music listening. Ear Hear. 1998;19(6):420-8.53. Spoor A, Passchier-Vermeer W. Spread in hearing levels of non-noise exposed people at various ages. Int J Audiol. 1969; 8(2):328-36.

54. Folmer RL, Griest SE, Martin WH. Hearing conservation education programs for children: A review. J Sch Health. 2002;72(2):51-7.

Nicolae Petrescu (M.D. 2009, candidate) is currently a medical student at the University of Toronto. He received a B.Sc. (Conc.) in Biochemistry from the University of Ottawa. 